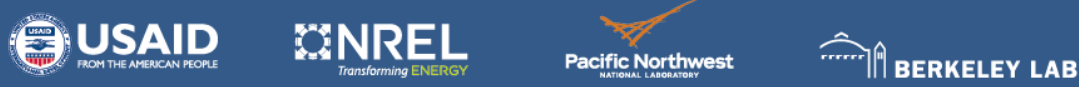

\title{
CHARTING A PATH FOR RESEARCH AND DEVELOPMENT OF RELIABILITY AND RESILIENCE IN SOUTH ASIA'S POWER SECTOR
}

Mohit Joshi, David Palchak, National Renewable Energy Laboratory

Russell Horowitz, Taryn Waite, Meredydd Evans, Sha Yu, Nathalie Voisin, Jan Alam, Pacific Northwest National Laboratory

Nihan Karali, Shruti Deorah, Nikit Abhyankar, Lawrence Berkeley National Laboratory November 2021

A product of the South Asia Group for Energy Contract No. AID-386-T-16-00002

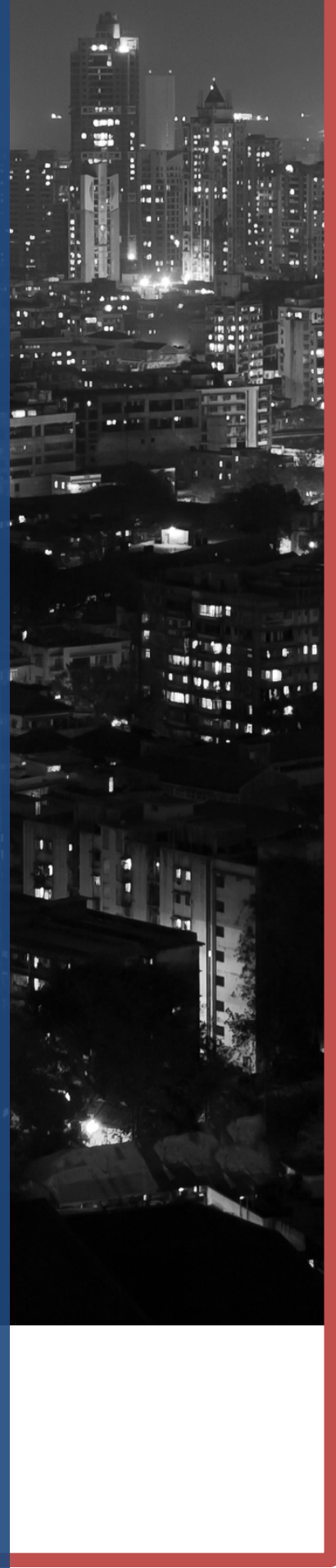




\section{CHARTING A PATH FOR RESEARCH AND \\ DEVELOPMENT OF \\ RELIABILITY AND \\ RESILIENCE IN SOUTH ASIA'S POWER SECTOR}

Mohit Joshi, David Palchak, National Renewable Energy Laboratory

Russell Horowitz, Taryn Waite, Meredydd Evans, Sha Yu, Nathalie Voisin, Jan Alam, Pacific Northwest National Laboratory

Nihan Karali, Shruti Deorah, Nikit Abhyankar, Lawrence Berkeley National Laboratory

November 2021

A product of the South Asia Group for Energy Contract No. AID-386-T-16-00002 


\section{NOTICE}

This work was authored, in part, by the National Renewable Energy Laboratory (NREL), operated by Alliance for Sustainable Energy, LLC, for the U.S. Department of Energy (DOE) under Contract No. DEAC36-08GO28308. Funding provided by the United States Agency for International Development (USAID) under Contract No. AID-386-T-16-00002. The views expressed in this report do not necessarily represent the views of the DOE or the U.S. Government, or any agency thereof, including USAID.

This report is available at no cost from the National Renewable Energy Laboratory (NREL) at www.nrel.gov/publications.

U.S. Department of Energy (DOE) reports produced after 1991 and a growing number of pre-1991 documents are available free via www.OSTI.gov.

Cover photo from iStock 120092576.

NREL prints on paper that contains recycled content. 


\section{Acknowledgments}

The authors thank Ilya Chernyakhovskiy and Jaquelin Cochran of the National Renewable Energy Laboratory (NREL) and Yang Ou and Abhishek Somani of the Pacific Northwest National Laboratory (PNNL) for their careful review and comments. The authors also thank the U.S. Agency for International Development (USAID) missions in India, Bangladesh, Nepal, and Sri Lanka for their feedback and coordination. We are also thankful to the Ministry of Power, Govt. of India for their support and review. Finally, we are grateful for the graphics and editorial support from Isabel McCan, Liz Breazeale, and Nicole Leon of NREL. 


\section{Abstract}

The power sector in South Asia faces several trends that have the potential to impact reliability and resilience. Rapidly increasing demand, coupled with an increasing reliance on variable renewable resources and the circular linkages with climate change, points to an increasing need to understand the extent of climate impacts on both electricity load and generation. These larger shifts are also coupled with opportunities near the grid edge that could have a large impact on system planning and operations, such as electrification of the transport sector, increased reliance on buildings to serve a broader set of loads and be flexible resources for utilities, more efficient use of industrial and agricultural loads, and growth in distributed energy resources such as rooftop solar and batteries. It is critical that, as this transformation takes place, expectations for reliability and resilience of the grid continue to increase in the region. The South Asia Group for Energy (SAGE), composed of the U.S. Agency for International Development (USAID), the U.S. Department of Energy, and three national laboratories, has been tasked with providing an overview of the research and development resources necessary to understanding the upcoming challenges for the power system as it pertains to reliability and resilience. This discussion paper identifies some of the key trends and connections that are important for power sector reliability and resilience and provides a starting point for eliciting feedback from power sector stakeholders about their experiences and needs. 


\section{List of Acronyms}

NAREM

NREL

SAGE

USAID
North American Energy Resilience Model

National Renewable Energy Laboratory

South Asia Group for Energy

U.S. Agency for International Development 


\section{Table of Contents}

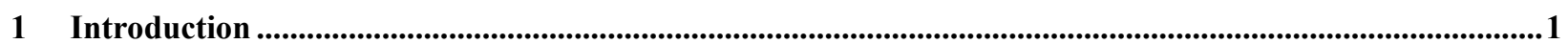

2 Challenges to Grid Reliability and Resilience in South Asia ....................................................................2

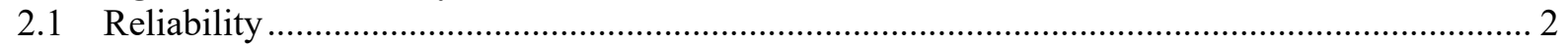

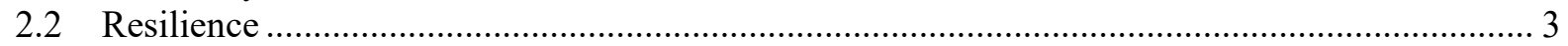

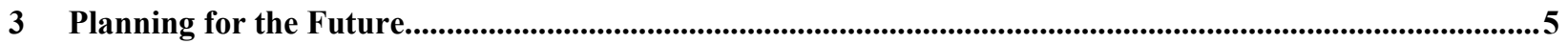

4 Next Steps for Research and Development .........................................................................................

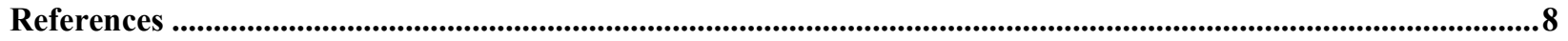




\section{List of Figures}

Figure 1. Hourly load from a peak load day in July in Delhi, 2010-2018 ............................................... 2

Figure 2. Extreme events from 1970-2020, totaled across all countries in South Asia.............................. 4

Figure 3. Forces and feedbacks acting on power system reliability and resilience ................................... 5 


\section{Introduction}

Power systems in South Asia are rapidly evolving to increase reliability and resilience in the face of climate change impacts, continued demand growth, emerging technologies, and increased renewable energy generation. Demand for electricity across the region has grown rapidly in recent history, in step with rising incomes, with a continued growth of roughly $5 \%$ per year expected in coming years (SLME 2021; IEA 2021; ADB 2017). New opportunities are developing for energy storage, distributed energy resources, and electrification of new sectors. By 2030, Bangladesh envisions up to $9 \mathrm{GW}$ of additional solar energy capacity (Chowdhury 2020), and India has a target to achieve $450 \mathrm{GW}$ of renewable energy capacity by the same year. Additionally, Nepal hopes to increase its renewable energy capacity by a factor of 10 (Government of Nepal 2020), and Sri Lanka looks to achieve a 70\% renewable energy share in electricity generation (SLME 2021). These trends will alter the magnitude and profile of electricity consumption and generation. As consumers rely on electricity for more of their energy needs and expect a constant supply, stakeholders will need to ensure that the power system is reliable, resilient, and sustainable.

Demand is expected to continue its rapid expansion in the region as incomes rise, with climate change adding to the trend, particularly in peak demand, through its effect on cooling appliance ownership and use. Extreme weather events such as heat waves, flooding, and droughts are predicted to occur more frequently in South Asia (Seneviratne et al. 2021), and the availability of water resources may vary from historical trends. As both droughts and downpours become more common, countries particularly dependent on hydropower for electricity generation, such as Bhutan and Nepal, will have increasingly variable generation. Nations with more coastal exposure, such as Maldives and Sri Lanka, will face greater threats to infrastructure, production capability, and supply chains from rising sea levels and tropical storms.

\section{Box 1: Key Areas for Stakeholder Input:}

- Challenges for maintaining reliability and resilience of future power system

- Incorporation of climate change into operations and planning

- Forecasting demand with changing load profiles

- Need for Integrated Resilience and Resource Planning.
All of these challenges require a holistic approach toward the planning and operation of power systems in South Asia. This has motivated the South Asia Group for Energy (SAGE), composed of the U.S. Agency for International Development (USAID), the U.S. Department of Energy, and three national laboratories, to identify key power sector opportunities for further research and development of innovative solutions to meet the needs of future power systems. The first phase of this project is to initiate stakeholder engagement across South Asia to discuss, identify, and prioritize the key issues most relevant to them. This discussion

paper is meant to identify various power system challenges to initiate the conversation with power sector stakeholders about how to build a reliable and resilient power system. Box 1 indicates a few key areas where we hope to receive input from stakeholders. The second phase of this project will focus on finding solutions to the key challenges prioritized by stakeholders in the first phase. 


\section{Challenges to Grid Reliability and Resilience in South Asia}

\subsection{Reliability}

Reliability is the most important aspect of a power system, comprising operational reliability and resource adequacy (NERC 2007). Operational reliability is the ability of the electric system to maintain service to customers despite sudden disturbances such as electric short circuits or unanticipated loss of system components. Resource adequacy is defined as the ability of the electric system to continuously supply the aggregate electric power requirements of electricity consumers (NERC 2007).

To ensure that South Asia's power sector will be able to reliably meet the region's rapidly growing demand, stakeholders must consider threats to the power sector from climate change. Integrated resource planning is needed to guarantee that generation additions keep pace with increasing electricity demand to enable round-the-clock reliable power supply to all consumers. This is already a challenge, but will become more so as changes to the climate affect resource availability. Planning will be more difficult if there is greater uncertainty about generation and demand response to trends in the climate and extreme weather.

Steady economic growth, expanded electricity access, and rising urbanization have led to rising electricity demand, particularly peak loads. Figure 1 shows the increase in peak loads in Delhi in July over recent years. The highest hourly load increased by $48 \%$ between 2010 and 2018 . In the next decade, India's peak load is expected to almost double, from $180 \mathrm{GW}$ in 2020 to $340 \mathrm{GW}$ in 2030, while the total energy demand is projected to increase by $75 \%$ over the same period (Abhyankar et al. 2021). Higher peak loads imply more expensive electricity costs because of lower system utilization factors. This is even more important in a decarbonized power system where load profiles will determine the amount of storage and flexible resources needed in the system. Load profiles will change due to the electrification of

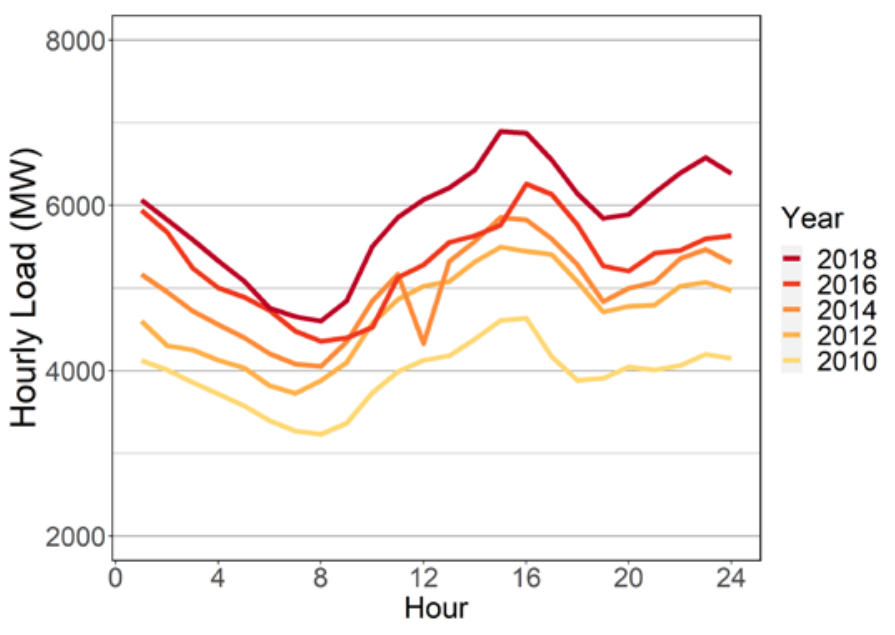

Figure 1. Hourly load from a peak load day in July in Delhi, 2010-2018

Source: (Abhyankar et al. 2021) industrial applications, agricultural activities, and vehicles, as well as the climate impacts on weatherdependent loads such as air conditioning.

Climate change will add to the uncertainty in supplying enough power to meet demand. Changes to precipitation, temperature, sea level, wind, and solar radiation patterns can all impact the availability of generation resources. Droughts may provide a particular challenge for South Asia, particularly in regions more dependent on hydropower or with high competition on scarce water resources for water-dependent thermal plants. While average annual rainfall is expected to increase throughout most of South Asia due to greater summer monsoon precipitation, increased total rainfall will be accompanied by a rise in seasonal and annual variability, leading to more extreme dry and extreme wet conditions (Vinke et al. 2017; Gupta et al. 2020). In March and April of 2019, Sri Lanka faced power cuts as droughts brought about water shortages that cut hydropower output by half (Aneez 2019). For hydropower plants in mountainous regions, glacial retreat represents another threat (Pathak 2010). A study on river flow regimes in Bhutan projects that hydropower plants in some catchments could lose up to $14 \%$ of river 
discharge available for hydropower production annually due to decreasing snowmelt and receding glaciers (Beldring and Voksø 2012). Thermal plants, which rely on water for cooling, may face increasing competition for water during dry spells, potentially increasing costs or constraining production (Zhou et al. 2018).

To holistically approach and plan for a reliable power system, updates may be required to existing regulations, standards, analysis tools, and technologies. As high penetrations of renewable energy and energy storage are reached, planners will need to consider the grid effects of new sources of variability, weather dependence, and system inertia. We have identified some key questions to start engaging stakeholders to discuss these challenges and decipher the future needs for a reliable and resource-adequate power grid. These questions are only meant to start the discussion and are not representative of all possible stakeholder concerns:

\section{Stakeholder Discussion Questions: Reliability}

- What measures need to be taken to ensure power system resource adequacy and reliability as the resource mix evolves and the climate changes?

- What measures need to be prioritized in the near term? Which are more important for the long term?

- How will climate change impact regional power generation, demand, delivery, and overall reliability?

- How much additional load will new connections, economic growth, electrification of transportation and industry, and appliance growth add to the grid? How will this further affect the diurnal and seasonal profile?

- How can demand response be leveraged to manage a growing load and a renewable energy-heavy grid?

\subsection{Resilience}

Resilience is the ability of the power system to withstand and reduce the magnitude and/or duration of disruptive events. This includes the capability to anticipate, absorb, adapt to, and/or rapidly recover from such events (National Infrastructure Advisory Council 2009). Resilience will rise in importance as consumers depend more on electricity and extreme events (heat waves, droughts, heavy precipitation, tropical storms) increase in intensity, frequency, and duration. This combined growth of demand and weather variability raises the potential for power system difficulties and failures. The historical increase in such events in South Asia is shown in Figure 2, with particularly stark increases in flooding and storms occurring in recent decades. Addressing the greater frequency and intensity of such events requires risk assessment, advance planning, and emergency preparedness, and post-event recovery procedures. Below, we highlight the potential impacts of high precipitation events and heat waves, as they are predicted to have widespread effects across geographies and sectors (ADB 2012). 


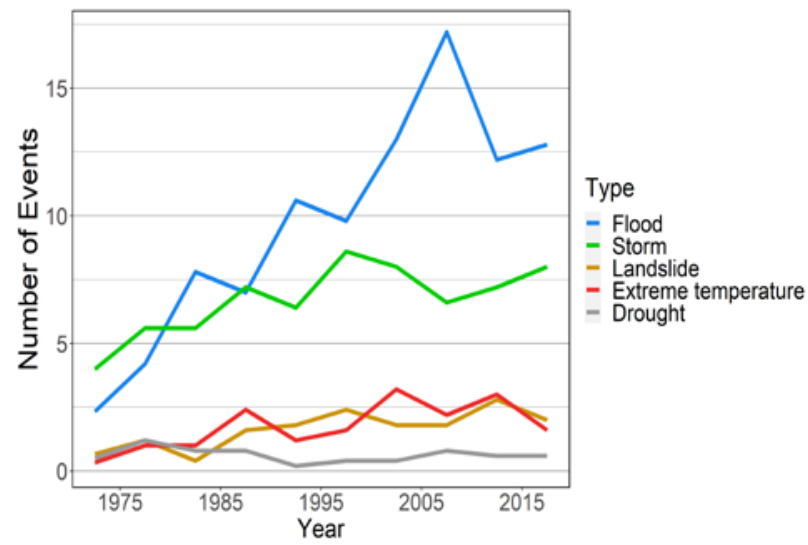

Figure 2. Extreme events from 1970-2020, totaled across all countries in South Asia

Source: (EM-DAT)
Stronger monsoon season rains are hazardous for the power system due to more frequent and destructive extreme precipitation events in South Asia (Gupta et al. 2020; Huo and Peltier 2020). The resulting increase in floods and landslides can damage energy sector infrastructure and supply chains, limiting both production and delivery. In August 2014, nearly 10\% of Nepal's hydropower supply was disconnected due to damage from a landslide caused by heavy rainfall (Bhatt 2017). The powerful wind and rains from storms present yet another growing threat; tropical cyclone SIDR in 2007 caused failures at all major power plants in Bangladesh, severe damage to wind power infrastructure, and destruction of electricity transmission lines (Shahid 2012).

Heat waves can create periods of high stress on both the demand and supply side of the power sector. In South Asia, the frequency and severity of heat waves is projected to increase, with an extra 12-18 days of extreme heat per year possible between 2020 and 2064 (Rohini et al., 2019). On the demand side, heat waves are projected to lead to higher peak loads as more and more customers seek protection from extreme temperatures. Although peak loads in South Asia are already greater in the summer, a relatively small proportion of the population currently owns air conditioners. In 2016 and 2018 only 5\% of residential buildings in India and $10 \%$ in Sri Lanka had central or room air conditioners, respectively (Abhyankar et al. 2017; Frost and Sullivan 2018). In July 2021, India's instantaneous power demand hit a historic high of $200 \mathrm{GW}$, following increased use of air conditioners due to the high temperatures reached in northern India (Shah and Lolla 2021). On the supply side, elevated air and water temperatures during heat waves may deteriorate the performance of power plants and transmission and distribution systems (Añel et al. 2017). This coincident peak in demand and stress on supply can ultimately lead to power shortfalls, which is a major health concern during heat waves (Stone et al. 2021).

Regardless of the specific region being discussed, climate change is a growing source of uncertainty, risk, and potential deviation from business-as-usual operation. Operational and investment decisions will need to work towards building a power system resilient to a changing, and often more destructive, climate. With this in mind, we have developed the following questions to engage with stakeholders:

\section{Stakeholder Discussion Questions: Resilience}

- How are power systems currently prepared to withstand and recover quickly from extreme events?

- What new measures need to be taken to ensure grid resiliency as demand and extreme event intensity increase?

- How will a high renewable energy share affect grid vulnerability and ability to withstand extreme events? 


\section{Planning for the Future}

To improve the resilience and reliability of the future power system, stakeholders need integrated planning processes capable of accounting for all the factors that will affect their operations. The continued growth of renewable energy and demand entail a massive expansion of investment, infrastructure, and generation capacity. More variable energy sources and loads will create new operational challenges, while climate change adds uncertainty to resource availability, electricity demand, and infrastructural security. This new environment necessitates holistic and coordinated planning processes by stakeholders across South Asia.

Demand forecasting is critical to ensure cost-effective system planning and reliable grid operation. Accurate forecasting allows grid operators and planners to achieve higher efficiency and reliability in system planning and grid operations. It is also key to keep consumer costs low by ensuring that utilities procure a least cost mix of resources to meet the demand reliably. There are many factors that can drive uncertainty in demand growth, such as appliance ownership and usage, new sectoral loads, changing weather patterns, and demand response. While some of these factors already impact demand profiles, others such as electric vehicle adoption, industrial electrification, climate change, and renewable energy penetration will increasingly alter the load in the future.

An additional challenge for planners is that the trends facing the power system in South Asia do not act in isolation, but rather must be viewed as a connected set of drivers acting on the system. To maintain grid reliability and resilience, it will be crucial for demand and supply forecasts to be synchronous. Power generation infrastructure decisions must consider demand projections, renewable energy targets, availability of fuels, and protection against damage and performance deterioration from climate impacts. A schematic representation of these interconnections is shown in Figure 3, where various forces challenge the ability to create a reliable and resilient power system.

One planning approach for dealing with this complexity,

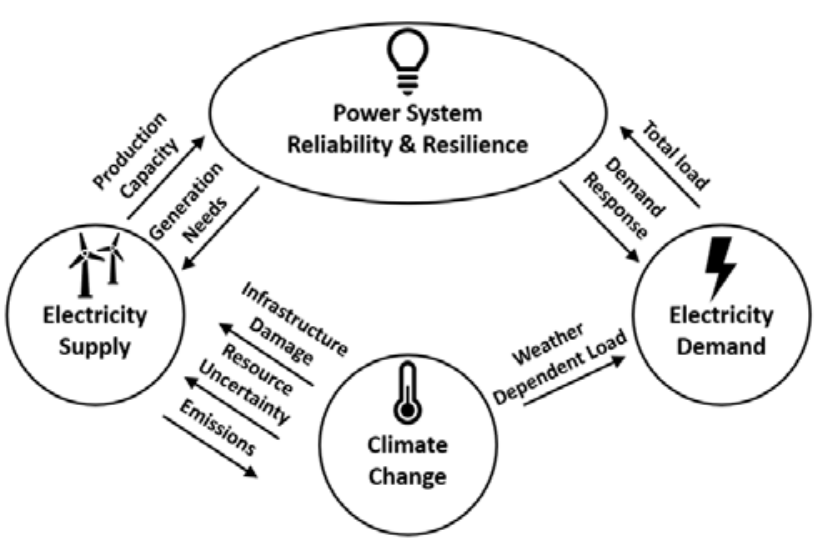

Figure 3. Forces and feedbacks acting on power system reliability and resilience

Integrated Resource and Resilience Planning creates a long-term investment plan that considers various uncertainties and risks, as well as policy, social, and environmental factors. It attempts to engage all relevant stakeholders to create a least-cost plan that can be regularly updated (Boyer et al. 2020). Regardless of the specific planning strategy utilized, it is important that stakeholders are armed with best-available data and projections to make evidence-based decisions. This may require addressing systemic challenges to data usage; for example, lack of consumer metering and unreliable metering, better load research and surveys by utilities and third parties, appliance-level consumption analysis, and availability of feeder and sub-feeder-level metering data.

In addition to approaches to improve forecasting, cooperation and communication can be beneficial across nations, states, sectors, and stakeholders. A wide footprint of power grids with regional diversity in climate, resources, and load can provide a buffer of reliability and resiliency to a power system.

Knowledge sharing, cross-border electricity trade, regional grid connection, and standardized procurement and planning practices are all options that could result in a more reliable, resilient, and consistent system. We want to understand and discuss the opportunities and needs in South Asia to 
improve interconnections for sharing resources, coordinating operations, and cooperating in crises. Below are questions aimed at better understanding stakeholder planning processes and need:

\section{Stakeholder Discussion Questions: Planning}

- What approaches can be taken to better incorporate emerging challenges into an integrated planning process, both across sectors and geographies?

- Does long-term planning currently account for climate change?

- In what ways can the existing load forecasts be improved? How can they be redesigned to better account for uncertainties in load? How can demand response be incorporated in load forecasting?

- What methods of cooperation or coordination, within or between countries, would be most beneficial to stakeholders? 


\section{Next Steps for Research and Development}

The application of SAGE capabilities to address power sector challenges will depend on the needs of stakeholders. The national laboratories comprising SAGE have a wealth of experience and knowledge developing and applying tools to improve planning and decision-making. These tools include power system-specific models that provide a detailed understanding of grid operations, as well as broader energy-economic models that capture interactions between the power system and energy, climate, land use, and water systems. They can be used to assess existing infrastructure operational stress, energy system transitions, and the resilience of the grid to extreme events, among other capabilities.

Based on stakeholder feedback, SAGE can assess which solutions can answer unresolved questions and support decision-making. This may involve repurposing tools to capture regional specificities, combining models to link different types and levels of system representation, collaborating with country-specific stakeholders to take advantage of their existing data/models, and/or developing new tools for stakeholders. An example project to provide inspiration for SAGE is the North American Energy Resilience Model. This is an effort in the United States among multiple national laboratories to develop a modeling system for planning and real-time analysis of the energy system's response to extreme events and energy disruptions. Another effort across multiple national laboratories and universities is Integrated Multisector Multiscale Modeling, where capabilities are being developed to understand the covulnerabilities and co-resilience of the energy-water-land systems to climate, technological, and socioeconomics changes in the $21^{\text {st }}$ century. Tools and lessons resulting from these projects may inform power sector work in the South Asian context.

Next steps will include meetings to understand the perspectives and experiences of those working directly in the power sector. Using the feedback from those meetings and this discussion paper, the national laboratories and selected partners will write three more detailed reports related to the power sector in South Asia: on the resiliency of the power sector, climate impacts, and electricity demand. The findings from those works and meetings with stakeholders will guide the creation of a research plan to be conducted by the SAGE laboratories in collaboration with stakeholders. 


\section{References}

1. Sri Lanka Ministry of Environment. (2021). Updated Nationally Determined Contributions. https://www4.unfecc.int/sites/ndestaging/PublishedDocuments/Sri\%20Lanka\%20First/NDCs\%20 of $\% 20$ Sri\%20Lanka-2021.pdf.

2. International Energy Agency. (2021). India Energy Outlook 2021. https://www.iea.org/reports/indiaenergy-outlook-2021.

3. Asian Development Bank. (2017). Nepal Energy Sector Assessment, Strategy, and Road Map. http://dx.doi.org/10.22617/TCS178936-2.

4. Chowdhury, S.A. (2020). National Solar Energy Roadmap, 2021 - 2041. Centre for Energy Research, UIU.

http://www.sreda.gov.bd/sites/default/files/files/sreda.portal.gov.bd/notices/0d5c65ae 8427 4e8a bb2f_8f9f7995ea3c/2020-12-17-08-53-0083599fc2338771fa568c849b302834.pdf.

5. Government of Nepal. (2020). Second Nationally Determined Contribution (NDC).

https://www4.unfccc.int/sites/ndcstaging/PublishedDocuments/Nepal\%20Second/Second\%20Nat ionally $\% 20$ Determined $\% 20$ Contribution $\% 20(\mathrm{NDC}) \% 20-\% 202020 . \mathrm{pdf}$.

6. Seneviratne, S. I., X. Zhang, M. Adnan, W. Badi, C. Dereczynski, A. Di Luca, S. Ghosh, I. Iskandar, J. Kossin, S. Lewis, F. Otto, I. Pinto, M. Satoh, S. M. Vicente-Serrano, M. Wehner, and B. Zhou. (2021). "Weather and Climate Extreme Events in a Changing Climate." In: Climate Change 2021: The Physical Science Basis. Contribution of Working Group I to the Sixth Assessment Report of the Intergovernmental Panel on Climate Change [Masson-Delmotte, V., P. Zhai, A. Pirani, S. L. Connors, C. Péan, S. Berger, N. Caud, Y. Chen, L. Goldfarb, M. I. Gomis, M. Huang, K. Leitzell, E. Lonnoy, J. B. R. Matthews, T. K. Maycock, T. Waterfield, O. Yelekçi, R. $\mathrm{Yu}$ and B. Zhou (eds.)]. Cambridge University Press. In Press.

7. North American Electric Reliability Corporation. (2007). Definition of "Adequate Level of Reliability". https://www.nerc.com/docs/pc/Definition-of-ALR-approved-at-Dec-07-OC-PC-mtgs.pdf.

8. Government of India, Ministry of Power, Central Electricity Authority. (2017). Report on Nineteenth Electric Power Survey of India.

9. Abhyankar, N. et al. (2021). FRI Modeling Study Report. Unpublished manuscript.

10. Vinke, K., Martin, M. A., Adams, S., Baarsch, F., Bondeau, A., Coumou, D., Donner, R. v., Menon, A., Perrette, M., Rehfeld, K., Robinson, A., Rocha, M., Schaeffer, M., Schwan, S., Serdeczny, O., \& Svirejeva-Hopkins, A. (2017). Climatic risks and impacts in South Asia: extremes of water scarcity and excess. Regional Environmental Change, 17(6), 1569-1583. https://doi.org/10.1007/s10113-015-0924-9.

11. Gupta, V., Singh, V., and Jain, M. K. (2020). Assessment of precipitation extremes in India during the 21st century under SSP1-1.9 mitigation scenarios of CMIP6 GCMs. Journal of Hydrology, 590(April), 125422. https://doi.org/10.1016/j.jhydrol.2020.125422.

12. Aneez, S. (2019). "Sri Lanka's drought, failure to raise power capacity force nationwide power cuts." Reuters. https://www.reuters.com/article/us-sri-lanka-power/sri-lankas-drought-failure-to-raisepower-capacity-force-nationwide-power-cuts-idUSKCN1R61WG. 
13. Pathak, M. (2010). "Climate Change: Uncertainty for Hydropower Development in Nepal.” Hydro Nepal Journal of Water Energy and Environment, 6, 31-34.

14. Beldring, S., and Voksø, A. (2012). "Climate Change Impact on Flow Regimes of Rivers in Bhutan and Possible Consequences for Hydropower Development." Hydro Nepal Journal of Water Energy and Environment, 11, 67-68. https://doi.org/10.3126/hn.v11i0.7167.

15. Zhou, Q., Hanasaki, N., Fujimori, S., Yoshikawa, S., Kanae, S., and Okadera, T. (2018). "Cooling water sufficiency in a warming world: Projection using an integrated assessment model and a global hydrological Model." Water, 10(7), 1-14. https://doi.org/10.3390/w10070872.

16. National Infrastructure Advisory Council. (2009). Critical Infrastructure Resilience Final Report and Recommendations. https://www.cisa.gov/sites/default/files/publications/niac-criticalinfrastructure-resilience-final-report-09-08-09-508.pdf.

17. EM-DAT: The Emergency Events Database. Université catholique de Louvain (UCL). CRED, D. Guha-Sapir. www.emdat.be.

18. Asian Development Bank. (2012). Climate Risk and Adaptation in the Electric Power Sector. http://hdl.handle.net/11540/887.

19. Huo, Y., and Peltier, W. R. (2020). "Dynamically downscaled climate change projections for the South Asian monsoon: Mean and extreme precipitation changes and physics parameterization impacts." Journal of Climate, 33(6), 2311-2331. https://doi.org/10.1175/JCLI-D-19-0268.1.

20. Bhatt, R. P. (2017). "Hydropower Development in Nepal - Climate Change, Impacts and Implications." In Basel I., Renewable Hydropower Technologies. InTech. https://doi.org/10.5772/66253.

21. Shahid, S. (2012). "Vulnerability of the power sector of Bangladesh to climate change and extreme weather events." Regional Environmental Change, 12(3), 595-606. https://doi.org/10.1007/s10113-011-0276-z.

22. Rohini, P., Rajeevan, M., and Mukhopadhay, P. (2019). "Future projections of heat waves over India from CMIP5 models." Climate Dynamics, 53(1), 975-988. https://doi.org/10.1007/s00382-019$\underline{04700-9 .}$.

23. Abhyankar, N., Shah, N., Letschert, V., \& Phadke, A. (2017, September 13-15). Assessing the costeffective energy saving potential from top-10 appliances in India. 9th International Conference on Energy Efficiency in Domestic Appliances and Lighting (EEDAL), University of California, Irvine. https://etapublications.lbl.gov/sites/default/files/india appliance ee potential eedal conference paper_0.p df.

24. Frost and Sullivan (2018). Sri Lankan Air Conditioning Market, Forecast to 2022. ID: 4715546.

25. Shah, K. and Lolla, A. (2021). Institute for Energy Economics and Financial Analysis. https://ieefa.org/ieefa-understanding-indias-latest-peak-power-demand-record/. 
26. Añel, J. A., Fernández-González, M., Labandeira, X., López-Otero, X., and de la Torre, L. (2017). "Impact of cold waves and heat waves on the energy production sector." Atmosphere, 8(11). https://doi.org/10.3390/atmos8110209.

27. Stone, B. Jr., Mallen, E., Rajput, M., Gronlund, C. J., Broadbent, A. M., Krayenhoff, E. S., Augenbroe, G., O'Neill, M. S., and Georgescu, M. (2021). "Compound Climate and Infrastructure Events: How Electrical Grid Failure Alters Heat Wave Risk.” Environ Sci Technol, 55(10):69576964. doi: 10.1021/acs.est.1c00024.

28. Boyer, M., Haydel, J., and Hellmuth, M. (2020). Ghana's Integrated Resource and Resilience Planning (IRRP) Program. U.S. Agency for International Development. https://pdf.usaid.gov/pdf docs/PA00X3HT.pdf. 
Monali Hazra

U.S. Agency for International Development

Email:mhazra@usaid.gov

David Palchak

National Renewable Energy Laboratory

Email: david.palchak@nrel.gov

Meredydd Evans

Pacific Northwest National Laboratory

Email: m.evans@pnnl.gov

Shruti Deorah

Lawrence Berkeley National Laboratory

Email: smdeorah@lbl.gov

NREL/TP-6A40-81223 | November 2021
The South Asia Group for Energy (SAGE) is a consortium comprising USAID, the United States Department of Energy and three national laboratories: the Lawrence Berkeley National Laboratory (LBNL), the National Renewable Energy Laboratory (NREL) and the Pacific Northwest National Laboratory (PNNL). The consortium represents excellence in research and international development in the energy sector to advance the Asia Enhancing Development and Growth through Energy (Asia EDGE) priorities in the South Asia region. 